\title{
Defending public health policies from objections of paternalism
}

\author{
Matthew Greenacre \\ Faculty Reviewer: Jacob Shelley, LLB, LLM, SJD(c) (Faculty of Law and School of Health Studies in Faculty of Health Sciences)
}

\section{ABSTRACT}

Paternalism is defined as an action that infringes a person's liberty and is performed without their consent, but is intended to improve a person's welfare. As such, many public health policies are criticized as being paternalistic because they attempt to influence citizens' behaviours to prevent disease or injury. Therefore, public health advocates ought to be aware of what justifies paternalism. Arguments based on the harm principle are the strongest defense of paternalistic policies in Western culture, but reinforcing an individual's integrity and improving social welfare may also be considered sufficient reasons. In practice, what is considered sufficient reason for paternalism depends upon the culture of the affected society. Collectivist cultures are willing to accept a paternalistic policy in exchange for a better quality of life for their whole community, but individualist cultures are very averse to such a trade. This article provides examples of how these principles arise in the debate over implementing anti-obesity legislation. Advocates must recognize paternalism and know when it is acceptable in order to defend public health policy from that common criticism.

\section{INTRODUCTION}

Mandating seat belts, controlling industrial pollution, and outlawing smoking in public places are three familiar ways that legislation has been used to prevent disease. Despite significantly reducing morbidity and mortality from infectious and respiratory diseases, when many public health laws are initially proposed, they are met with the objection that they are too paternalistic. ${ }^{1-4}$ For example, when New York City decided to limit the portion size of soda, the municipal government was called a "nanny state". ${ }^{3}$ As Canadians debate a tax on sugar and fatty foods, critics claim such measures are paternalistic and futile. ${ }^{5,6}$

It is important for health professionals advocating for public health policy to know whether a policy is paternalistic, be able to judge whether that paternalism is justified, and be able to defend their policy if it is attacked on those grounds. This article will explain what paternalism is, its common criticisms, and instances when it can be justified. Currently debated anti-obesity policies will be used as a case study.

\section{WHAT IS PATERNALISM?}

A policy is paternalistic when it affects a person without their consent and it curtails their liberty, but is imposed because it is expected to benefit them. ${ }^{1,7}$ For example, a ban on sugary drinks might be intended to protect people from obesity or diabetes, but is nev- ertheless paternalistic because some citizens may not consent to it and the ban would limit their freedom to drink a beverage they may otherwise choose.

However, the spectrum of paternalism ranges between hard and soft. The hardness of paternalism depends on the degree to which that policy restricts individual choice or behaviour. Policies such as forced isolation of patients carrying particularly virulent infectious diseases are at one end of the spectrum, called hard paternalism. Policies that do not seek to control individuals outright, but instead use incentives or disincentives to encourage healthier choices are towards the soft end of the paternalism spectrum. The softest forms of paternalism include policies that help to ensure that healthier options are available for people to choose if they wish, and provide information to help individuals improve their decision making. ${ }^{1,8,9}$ While harder forms of paternalism typically place more obvious limitations on the individual, paternalistic policies of any kind may present compromises to personal autonomy.

\section{WHAT ARE THE CRITERIA FOR JUSTIFYING PATERNALISM?}

Paternalism is criticized on the grounds that (a) no one is better placed to judge the best interests of a person than that individual themself, and (b) paternalism reduces one's ability to be an autonomous being. ${ }^{1}$ Autonomy is a key part of human well-being, a precondition for moral agency (i.e., to blame or praise a person for their actions, they must be their own), and a prerequisite for consenting to the principles of justice that govern a society. ${ }^{10,11}$ And so, individual autonomy is inviolable, particularly in Western cultures. ${ }^{10}$ The harder the paternalism is within a particular policy, the stronger the justification must be. ${ }^{8}$

To be acceptable to most Western populations, a paternalistic policy ought to either prevent individuals from harming one another (e.g., criminal law against theft), improve the welfare of society (e.g., imposing taxes and using them for social services), ${ }^{8}$ or intervene when individuals are failing to act autonomously or in their own best interests (e.g., controlling access to addictive drugs). ${ }^{12}$ Of these, preventing individuals from harming each other is often considered to be the strongest justification for paternalism. This is often discussed as the harm principle $;^{12}$ as defined by the philosopher J.S. Mills, the harm principle states that "the only purpose for which power can be rightfully exercised over any member of a civilized community, against his will, is to prevent harm to others." ${ }^{13}$ If a policy does not sufficiently reduce harm between citizens, if it fails to improve society's welfare, or if it infringes individual autonomy, then it is unlikely to be acceptable to a Western population.

Defence of Hard Paternalism: The Argument from Integrity

In Western societies, hard paternalism is usually only ever war- 
ranted by the harm principle. A person should not be stopped from voluntarily consuming too many calories and becoming obese by coercive measures, such as bans. However, paternalistic policy may also be sufficiently justified if it stops someone from inadvertently interfering with their greater life goals. This is the "argument from integrity" defence of hard paternalism. ${ }^{1}$ Paternalistic legislation, like a ban or a heavy tax, may be defended on the grounds that it helps people maintain their integrity, where integrity is the ability to remain consistent in one's desires for one's future self. This is a primary justification for mandatory seatbelt laws. ${ }^{1}$ Imagine that a person does not like wearing their seatbelt. Also assume that being injured or killed in a motor vehicle accident is not what they hope the future will bring. The argument from integrity justifies the government forcing the general public to use seatbelts, a slight inconvenience, because the seatbelt very effectively limits the risk of serious injury, which we can assume to be almost universally undesirable. ${ }^{1,14}$

\section{Public Opinion}

When a paternalistic policy does not unambiguously prevent harm between people, what counts as a sufficient justification of the policy depends on an individual's values. It is helpful to consider these values on the spectrum between collectivism and individualism. Collectivists are generally more willing to grant government more latitude to enact policies that embrace hard paternalism in exchange for greater overall wellbeing for the majority of society. Individualists, however, believe that the only role of state is to ensure liberty, property rights, and freedom from interference from others. ${ }^{8,10}$

Canada is considered by many to be an individualist country, but strong support for liberal policies also demonstrate national favour for collectivist values. ${ }^{15}$ Canada's liberalness means that the majority of its population finds policies that improve society's welfare to be sufficient reasons for paternalism. This includes support for policies aiming to reduce rates of obesity. As of 2012, a poll of 512 young adults found strong support for anti-obesity policies, ${ }^{15}$ and a poll by the Public Health Agency of Canada had found that $40 \%$ of Canadians would support a tax on soda if the funds were used to fight childhood obesity. ${ }^{16}$

\section{Example of Improving Limited Autonomy: The Toxic Food En- vironment}

Public health policies aimed at educating or influencing behaviour in children are often viewed as not paternalistic simply because children do not have the same level of autonomy as adults. Food advertising can significantly shape the long term eating habits of children and what kinds of foods parents purchase. ${ }^{17,18}$ Regulating marketing to children is considered acceptable because it does not disrespect the autonomous choices of children, as it would an adult, but rather seeks to prevent children from developing unhealthy food preferences. ${ }^{1,7}$

Advertising to children is just one component of the many factors that drive the obesity epidemic and limit the ability of individuals to maintain a healthy diet. Collectively, these factors constitute the toxic food environment. For example, the fact that fattening, energy dense foods are cheap and fruits and vegetables are relatively expensive imposes a strong financial barrier to healthy diets. ${ }^{19,20}$ The complexity of nutritional information can also be a barrier to making healthy dietary choices, so it is recommended that nutritional information be simplified to make it more easily understandable. ${ }^{17,21}$ Communities that have close proximity to fast food restaurants, but limited access to parks, recreational facilities, and safe places to walk and play, naturally have a hard time being active, and so are at higher risk of obesity. ${ }^{2,17}$

Government interventions that ameliorate factors that drive the obesity epidemic may actually improve autonomy, and could therefore be justified despite objections of paternalism. For example, improving the ability of consumers to use objective nutritional information improves their ability make voluntary decisions about diet. Removing financial and physical barriers to healthy diets and exercise can improve one's ability to choose and maintain that lifestyle. ${ }^{1}$ Policies that provide information and give citizens financial or physical opportunities to pursue a healthy life, but do not thrust those opportunities on them, may be argued to be a very soft form of paternalism because they actually increase their autonomy rather than infringe it. $^{8}$

\section{CONCLUSIONS}

Recognition of the principles and factors that make paternalism acceptable is crucial to the development and advocacy of public health policy. The more coercive the policy, the harder that form of paternalism is and the stronger the justification would need to be. For a health professional considering whether to advocate for a hard paternalistic policy, it is important to recognize that in Western cultures, hard paternalism is generally only justified by the harm principle and the argument from integrity. Public health policies that alleviate the social or physical barriers that prevent individuals from making and pursuing healthy choices may also be seen as a justified use of paternalism. However, the acceptable level of paternalism depends on the culture and values of the society being regulated. Collectivist cultures are willing to exchange an improvement in the welfare of the majority for a reduction in individual autonomy, whereas individualist cultures are not. Whether working internationally, in a remote part of Canada, or one's own neighbourhood, proposing policies that are sensitive to community values are far more likely to succeed than uncompromising regulations. However, appropriate paternalistic public health policy may be justified and defended from claims that the state is overreaching.

\section{REFERENCES}

1. McGuinness SA. Time to Cut the Fat : The Case for Government Anti-Obesity Legislation. J Law Health. 2012;25(41):42-83.

2. Gostin LO. Law as a Tool to Facilitate Healthier Lifestyles and Prevent Obesity. JAMA J Am Med Assoc. 2016;297(1):87-90.

3. Wiley LF, Berman ML, Blanke D. Who's your nanny? Choice, paternalism and public health in the age of personal responsibility. J Law Med Ethics. 2013 Mar;41(Suppl 1):88-91.

4. Jochelson K. Nanny or Steward? The role of government in public health. London; 2005 
5. Luciani, P. Don't expect government to win the war on obesity. The Globe and Mail. 2014 Apr 21 [cited 2016 Apr 12]. Available from: http:// www.theglobeandmail.com/opinion/dont-expect-government-to-winthe-war-on-obesity/article18075169/

6. Brown, J. Sugar Tax: obesity fix or misguided paternalism? CBC 2015 Jul 17 [cited 2016 Apr 12]. Available from: http://www.cbc.ca/news/ sugar-tax-obesity-fix-or-misguided-paternalism-1.2786724

7. Pratt K. A Constructive Critique of Public Health Arguments for Anti-obesity Soda Taxes and Food Taxes. Tulane Law Rev. 2012;87:73140.

8. Calman K. Beyond the "nanny state": Stewardship and public health. Public Health. 2009;123:6-10.

9. Friedman DA. Public Health Regulation and the Limits of Paternalism. Conneticut Law Rev. 2014;46(5):1687-770.

10. Gillon R. Ethics needs principles-four can encompass the rest-and respect for autonomy should be "first among equals." J Med Ethics. 2003;(29):307-13.

11. Buchanan DR. Ethics in Public Health Research Autonomy, Paternalism, and Justice: Ethical Priorities in Public Health. Heal Policy Ethics. 2008;98(1):15-21.

12. Sunstein CR. Legal Interference with Private Preferences. Univ Chicago Law Rev. 1986;53(4):1129-74.

13. Mill, J.S. On Liberty. 4th ed. London: Longman, Roberts \& Green, 1869. 474p.

14. Parmet WE. Beyond Paternalism: Rethinking the Limits of Public Health Law. Conneticut Law Rev. 2014;46(5):1771-94.

15. Lange R, Faulkner G. Support for obesity policy: The effect of perceptions of causes for obesity and national identity in Canada. Open J Prev Med. 2012;2(4):478-89.

16. Gratzer D, Guénette J. Are Soda Taxes A Cure For Obesity? Montreal: The Montreal Economic Institute; 2012. p. 1-4.

17. Eisenberg MJ, Atallah R, Grandi SM et al. Legislative approaches to tackling the obesity epidemic. CMAJ. 2011;183(13):1496-500.

18. Raine KD, Lobstein T, Landon J. Restricting marketing to children: Consensus on policy interventions to address obesity. J Public Health Policy. 2013;34(2):239-53.

19. Faulkner GEJ, Grootendorst P, Nguyen VH, et al. Economic instruments for obesity prevention: results of a scoping review and modified delphi survey. Int J Behav Nutr Phys Act. 2011;8(1):109.

20. Drewnowski A, Darmon N. The economics of obesity: dietary energy density and energy cost. Am J Clin Nutr. 2005;82(12):265-73.

21. Gortmaker SL, Swinburn B, Levy D, et al. Changing the Future of Obesity: Science, Policy and Action. Lancet. 2011;378(9793):838-47. 